\title{
Mineração
}

\section{Bases para o desenvolvimento sustentável e competitivo da indústria de agregados nas regiões metropolitanas do país - Parte 1}

\author{
(Guidelines for the competitive performance and sustainable \\ development of quarries located in Brazilian metropolitan \\ urban conglomerates - Part 1)
}

Gilberto Dias Calaes

Economista, Pós-Graduado em Economia Mineral e Doutorado em Geologia Econômica e Regional Diretor de ConDet Ltda. E-mail: condet@terra.com.br

\author{
Bernardo Piquet Carneiro Neto \\ Engenheiro de Minas, Pós-Graduado em Engenharia Econômica e Especialista em Agregados \\ Diretor de Minaserv Ltda.E-mail: bpiquet@terra.com.br
}

Cláudio Margueron

Engenheiro de Minas, Ex-Professor Titular de Economia Mineral do Departamento de Geologia da UFRJ Atual professor visitante da UFRJ.E-mail: cmargueron@uol.com.br

José Alexandre Gurgel do Amaral Engenheiro de Minas e Metalurgia, Mestre em Meio Ambiente e especialista em gestão de resíduos Diretor de J.A. Consultoria Ltda.E-mail: flori@uninet.com.br

\section{Resumo}

O presente artigo encontra-se compreendido em duas partes. A primeira assinala a importância do planejamento estratégico e do ordenamento territorial na estimulação da competitividade e da sustentabilidade de empreendimentos produtores de agregados para a construção civil. A segunda parte, a ser publicada na próxima edição dessa revista, analisará o caso do parque produtor de brita da RMRJ, investigará os mecanismos alternativos de reconversão tecnológica, territorial e ambiental dos pólos produtores e apresentará propostas de políticas públicas para a promoção do desenvolvimento competitivo e sustentável da produção de agregados nas RMs do país.

Palavras-chave: Agregados, planejamento estratégico, ordenamento territorial, desenvolvimento sustentável, política e economia mineral.

\begin{abstract}
This paper comprises two parts. The first one states the importance of strategic planning and land management in stimulating the competitiveness and the sustainability of aggregate production for use in construction. The second part, to be published in the next issue of this magazine, will analyse the case of the crushed stone companies in the Rio de Janeiro metropolitan region as well the alternative mechanisms that may be applied to promote technological, land management and environmental improvements. It will also present proposals for public policies directed to promote the competitive and sustainable development in the aggregate production companies in the metropolitan regions of Brazil.
\end{abstract}

Keywords: Aggregate, Strategic Planning, Land management, Sustainable development, Mineral economics and policy. 


\section{Avaliação econômica e planejamento estratégico}

No contexto do planejamento e gestão de negócios, sobressaem os aspectos de caráter econômico e, nestes, a determinação de indicadores de decisão. Todo e qualquer projeto ou empreendimento deve dispor de um Plano de Negócio em que sejam estabelecidos, qualificados e quantificados os objetivos, os meios para atingi-los, os resultados a serem alcançados, bem como a forma de avaliá-los mediante a comparação de correspondentes benefícios e custos.

\subsection{Análise econômico-financeira como instrumento do planejamento de negócios}

A aplicação de conceitos e técnicas de análise econômico-financeira se afirma, cada vez mais, como procedimento essencial no planejamento e gestão de negócios, uma vez que propicia a consistente seleção de oportunidades e a tomada de decisão de investimentos relacionados à implantação, expansão e/ou modernização de projetos e empreendimentos, em bases competitivas e sustentáveis.

Toda e qualquer empresa atua em um ambiente de competição que oferece oportunidades, riscos e incertezas. Dado que as empresas atuam com recursos limitados, torna-se imprescindível selecionar a(s) melhor(es) oportunidade(s) de investimento entre as alternativas disponíveis. Decisões de investimento em bases competitivas e sustentáveis devem ser apoiadas em avaliações técnico-econômicas fundamentadas em uma base de conhecimento compreendida por três segmentos:

- Depósito Mineral: A estimação dos parâmetros relativos ao depósito mineral exige a realização de trabalhos de pesquisa mineral em estreita sintonia com ensaios tecnológicos de processamento e com estudos de engenharia de minas.

- Mercado: Os parâmetros relativos ao mercado estão sujeitos a variações determinadas por uma extensa lista de diferenciados fatores, sobressaindo, no setor de agregados, o comportamento das estruturas locais de oferta e demanda, o nível de organização da indústria e a capacitação gerencial e tecnológica dos produtores.

- Aspectos Institucionais: Os parâmetros de natureza institucional são também de grande sensibilidade devendo ser definidos e avaliados com absoluto rigor. Na indústria de agregados, destacam-se os aspectos regulatórios associados à legislação mineral e tributária, ao uso e ocupação do solo e ao meio ambiente.

Cabe ressaltar que decisões sintonizadas com a competitividade e com a sustentabilidade devem ser fundamentadas, necessariamente, na seleção, entre várias alternativas em con- sideração, daquela que assegure a otimização de objetivos estratégicos preestabelecidos no processo de planejamento. Na condução de tal processo interativo de otimização, a cada alternativa, em consideração, corresponde uma dada solução de processo, sujeita a correspondentes estimativas de investimentos e de custos operacionais, que, por sua vez, fundamentam uma respectiva simulação econômica.

Da análise dos indicadores de decisão determinados através de referidas simulações, torna-se possível verificar quais das alternativas em consideração atendem aos objetivos estratégicos e, portanto, devam ser selecionadas e, ao contrário, quais devam ser rejeitadas, por não atendê-los.

Torna-se possível determinar, entre as alternativas selecionadas, qual é a que estabelece a otimização dos objetivos de política pública ou de planejamento privado em consideração. Por outro lado - desde que os correspondentes objetivos de política pública e de planejamento empresarial sejam, simultaneamente, considerados - torna-se, também, possível selecionar a alternativa que, a um só tempo, otimize os objetivos públicos e privados.

\subsection{Planejamento estratégico, sustentabilidade e competitividade}

Ao incorporar metodologias de caráter prospectivo, holístico e sistêmico - o planejamento estratégico constitui a via de acesso a processos consistentes de desenvolvimento sustentável, assegurando as bases para o fortalecimento de posição competitiva de empresas, setores e regiões produtoras. A Figura 1 caracteriza elementos relevantes do processo de planejamento estratégico.

Os processos de planejamento e de tomada de decisão devem ser apoiados em análises sistematizadas de fatores estruturais (técnico-operacionais, gerenciais e econômicos) e sistêmicos (legais, institucionais, ambientais, infra-estruturais, fiscais e financeiros), que evidenciem as ações requeridas para assegurar a competitividade e a sustentabilidade, seja de sistemas produtivos regionais/setoriais, seja de projetos e empreendimentos individualizados.

O planejamento e a gestão estratégica de planos, programas, projetos, empreendimentos e negócios mínero-industriais devem compreender a análise de diferentes aspectos que condicionam a sua posição competitiva, especificamente no que se refere aos fatores:

- Intrínsecos: são aqueles que estão sob a esfera de decisão dos empreendedores, tais como capacitação para inovação, capacitação produtiva e recursos humanos.

- Extrínsecos: são fatores macroeconômicos, político-institucionais, regulatórios, infra-estruturais e sociais, relativos ao ambiente mais amplo com o qual o programa ou empreendimento se articula. 


\section{Planejamento, Desenvolvimento e Competitividade}

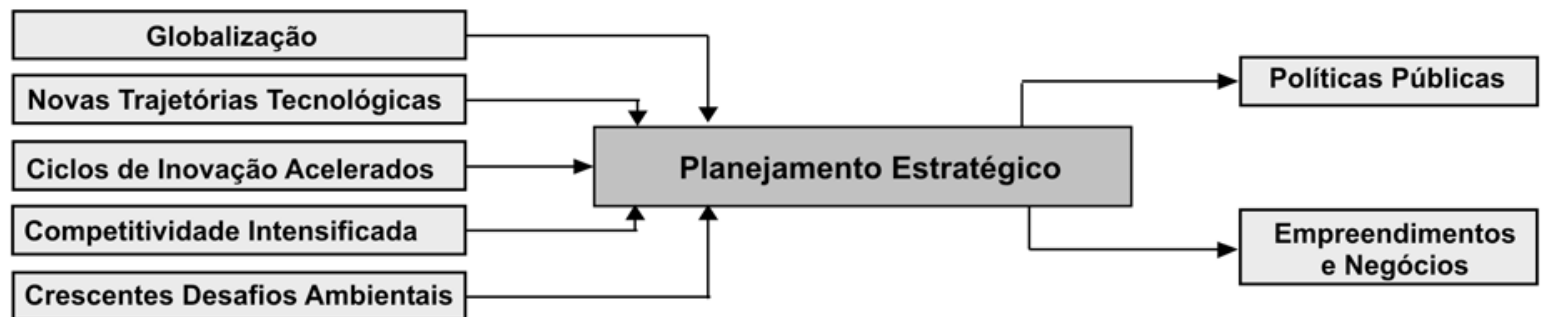

\section{Planejamento Estratégico:}

Caráter: prospectivo, holístico, integrativo e sistêmico.

Via de acesso: - ao desenvolvimento sustentável e, - ao fortalecimento de competitividade, de empresas, setores e regiões produtoras.

\begin{tabular}{|c|c|c|}
\hline $\begin{array}{c}\text { Planejamento } \\
\text { Estratégico }\end{array}$ & $\begin{array}{c}\text { Dosenvolvimento } \\
\text { Sustentável }\end{array}$ \\
Posição Competitiva
\end{tabular}

Figura 1 - Elementos de planejamento estratégico.

Para se estabelecer uma estratégia relativa a um empreendimento, empresa ou setor/região, é necessário definir a missão do negócio - expressa em termos de produto, mercado e escopo geográfico -, bem como os meios para desenvolver as necessárias e exclusivas competências, que irão assegurar vantagens competitivas e sustentáveis. O passo seguinte compreende a realização das análises dos ambientes internos e externos buscando identificar e avaliar os correspondentes fatores intrínsecos e extrínsecos que condicionam o potencial de desenvolvimento do negócio, sendo aqueles classificados em forças $\boldsymbol{e}$ fraquezas, e estes, em oportunidades $\boldsymbol{e}$ ameaças.

A partir da missão estabelecida e das análises dos ambientes interno e externo, torna-se possível formular a estratégia do empreendimento, empresa ou setor/região, sendo esta desdobrada em programas multi-anuais de ação. As etapas seguintes compreendem a avaliação dos programas estabelecidos, com a conseqüente alocação de recursos, através de orçamentos específicos. Na etapa final do processo, são definidos os indicadores de desempenho a serem utilizados na gestão estratégica.
Cabe ressaltar que o planejamento estratégico contribui para ampliar a disciplina de projeção e previsão de longo prazo, para disseminar o senso de unidade e direção, assim como para estimular o processo de aprendizado, de interação e de negociação em todos os níveis da organização.

\subsection{Planejamento e gestão estratégica no setor de agregados para construção}

O processo de planejamento e gestão estratégica de projetos e empreendimentos de agregados é iniciado com a análise dos ambientes interno e externo, de forma a identificar e avaliar suas forças $\boldsymbol{e}$ fraquezas, assim como suas oportunidades $\boldsymbol{e}$ ameaças.

\subsubsection{Ambiente interno}

A análise dos fatores intrínsecos ao empreendimento permite identificar e hierarquizar as forças e fraquezas que condicionam o seu potencial de desenvolvimento.

- Força: É a atual condição interna do projeto ou empreendimento de caráter estrutural e que contribui e contribuirá, consistentemente, para o alcance de objetivos relacionados à expansão da competitividade. Exemplos:

- Boa localização e características das reservas.

- Favorável disponibilidade e condições de acesso a tecnologias atualizadas.

- Sistema produtivo habilitado a operar segundo padrões competitivos.

- Adequada experiência, reputação e articulação do grupo empreendedor.

- Favoráveis condições de rentabilidade, capacidade de pagamento e geração de valor. 
- Fraqueza: É a atual condição interna do projeto ou empreendimento, de caráter estrutural e que dificulta e dificultará, substancialmente, a perseguição de correspondentes objetivos. Exemplos:

- Reservas minerais com características e/ou localização inadequadas.

- Dificuldades de suprimento de insumos, peças e materiais de reposição.

- Escassez de mão-de-obra especializada.

- Instabilidade do mercado.

\subsubsection{Ambiente externo}

A análise de fatores extrínsecos propicia construir uma visão das evoluções prováveis do ambiente externo, a fim de antecipar oportunidades e ameaças que condicionem a competitividade:

- Oportunidades são situações, tendências ou fenômenos externos ao projeto ou empreendimento, atuais ou potenciais, e que podem contribuir para a realização de seus objetivos permanentes. Exemplos:

- Condicionamento geológico favorável à expansão de reservas.

- Perspectiva de expansão e conquista de mercados.

- Facilidades de acesso a financiamentos adequados.

- Perspectivas de melhoria nas regulações de uso e ocupação do solo.

- Perspectivas de aprimoramentos na legislação mineral e/ou tributária e/ou ambiental.

- Ameaças são situações e tendências ou fenômenos externos ao projeto ou empreendimento, atuais ou potenciais, e que podem prejudicar substancialmente a consecução de seus objetivos. Exemplos:

- Perspectivas de retração de mercado.

- Perspectivas de agravamento do atual condicionamento regulatório/institucional, relativo a tributação, regimes de acesso à propriedade mineral, meio ambiente, etc.
1.3.3 Análise de competitividade

Condicionada ao grau de complexidade e às facilidades de informação de que se disponha, a análise estratégica da posição competitiva tem o propósito de construir um painel integrado e conclusivo, relativamente ao projeto, empreendimento, empresa ou setor objetivado, de tal forma a evidenciar as interações entre suas forças e fraquezas e suas ameaças e oportunidades. Tal análise deve ser realizada por meio da $M a-$ triz SWOT (Strengths, Weakness, Opportunities and Threats: Forças, Fraquezas, Oportunidades e Ameaças), consagrada metodologia de autoria de Porter (1986), cujo esboço simplificado encontra-se apresentado na Figura 2.

\subsubsection{Externalidades sob o ponto de vista da comunidade}

Na análise do condicionamento estratégico do projeto ou empreendimento, devem ser apreciadas as suas externalidades, envolvendo a apreciação dos seguintes aspectos:

- Atendimento a demandas reprimidas, com possíveis reduções de dependência e fortalecimento da economia regional.

- Efeitos de indução, integração e germinação de novas atividades econômicas.

- Contribuição para com o processo de desenvolvimento tecnológico.

- Aproveitamento racional do depósito e adequada valorização do seu conteúdo intrínseco.

- Geração de oportunidades de emprego, incremento de renda e arrecadação tributária.

- Harmonização do empreendimento ao meio natural e humano com o qual irá interagir.

Ao se proceder à análise de externalidades, cabe ter em vista as principais tendências e perspectivas dominantes no panorama global da indústria de agregados, tais como:
- Concentração da produção em grandes grupos verticalizados.

- Automação intensiva e gestão avançada.

- Britagem móvel, reduzindo o tráfego de caminhões.

- Aproveitamento de cavas de pedreiras e de areais para outros fins econômicos e sociais.

- Atuação de Universidades em P\&D: produtos, processos e desenvolvimento sustentável.

- Produção de areia de brita (AB) como alternativa à areia natural.

- Reciclagem de entulho de construção e demolição (ECD).

Com relação às duas últimas tendências assinaladas, cabe destacar:

Areia de Brita: A produção de areia de brita como subproduto (oriundo dos finos de britagem) ou como có-produto (a partir da rocha dura) vem se evidenciando como alternativa para assegurar o suprimento de agregados finos aos mercados, notadamente nos centros urbanos, onde o abastecimento de areia natural seja problemático.

Agregado oriundo de ECD: Areciclagem de entulho de construção e demolição é também uma alternativa que otimiza o processo de suprimento de agregados nos grandes centros urbanos, com importantes efeitos em termos de melhorias ambientais associadas ao ordenamento territorial e ao planejamento urbano.

\section{Ordenamento territorial no setor de agregados}

O ordenamento territorial é essencial para o planejamento e a gestão da produção de agregados para a construção, seja em nível de empreendimentos isolados ou de pólos produtores, notadamente os de regiões metropolitanas (RMs). 
Gilberto Dias Calaes et al.

\subsection{A questão do ordenamento territorial}

Ao analisar a estrutura de uso e ocupação do solo no nosso planeta, Regueiro (2006) assinala que os bosques ocupam cerca de $31 \%$ da superfície global, os pastos $25 \%$, as áreas agrícolas $11 \%$ e as áreas urbanas $10 \%$, destinando-se $23 \%$ a outros fins.

Face à expansão da população mundial e à sua continuada concentração em áreas urbanas, assim como à crescente escassez e complexidade do suprimento de recursos minerais - os conflitos da atividade mineral, com os processos de uso e ocupação do solo, vêm se intensificando. Tais desafios se acentuam na produção de materiais de emprego imediato na construção civil junto às áreas metropolitanas, tendo em vista o adensamento populacional e a expansão do consumo per capita, bem como por se tratar de materiais de baixo valor agregado, que não suportam grandes deslocamentos, sendo produzidos em áreas contíguas aos centros de consumo.

A partir do informe Brundtland (Nuestro Futuro Común, 1987) - que destacou a questão ambiental dos centros urbanos - a Cúpula do Rio de Janeiro (1992) e a de Estambul (1996) aprofundaram o debate sobre a sustentabilidade das cidades. Ao começar o século XXI, a sustentabilidade é um objetivo universal para a orientação do desenvolvimento urbano (Brand, 2001). Por outro lado, segundo Wackernagel (1996), as cidades são "as mais importantes fontes consumidoras de recursos e produtoras de resíduos" ... "alojam $45 \%$ da população mundial (78\% nos países sul-americanos)".

No contexto do desenvolvimento urbano, o processo de concentração demográfica, se por um lado estimula a queda do consumo per capita de energia, por outro expande a intensidade de consumo de materiais de emprego imediato na construção civil, cuja produção e distribuição pode oferecer sérios impactos em termos de consumo de ener- gia e de geração de resíduos, principalmente quando desprovidas de zoneamento adequado. No Brasil, devido à disponibilidade de recursos e reservas na maioria de suas RMs, as unidades produtoras de agregados tendem a se localizar o mais próximo ao mercado. Por outro lado, devido à deficiência das políticas de uso e ocupação do solo, verificam-se freqüentes conflitos de localização, à medida que ocorre o "sufocamento" das unidades produtoras, pelo avanço desordenado da urbanização.

Evidencia-se a necessidade de racionalizar métodos operacionais e de planejamento e gestão, objetivando desenvolver processos de produção e aperfeiçoar produtos, de forma a atenuar os impactos negativos associados à atividade produtiva.

\subsection{Sistema regulatório, tecnologia e ordenamento do território}

As questões relacionadas ao desenvolvimento sustentável nos pólos produtores de agregados encontram-se predominantemente associadas ao ordenamento do território, ou seja às políticas de uso e ocupação do solo, as quais são condicionadas pelo sistema regulatório e pela tecnologia de processo (lavra e beneficiamento) e de produto, onde se destacam as alternativas de produção de areia de brita $(\mathrm{AB})$ e de reciclagem de entulho de construção e demolição (ECD).

\subsubsection{Sistema regulatório}

Sob o ponto de vista regulatório, evidencia-se que a inexistência de programas de zoneamento, que estabeleçam áreas reservadas para a produção de agregados nas RMs, sujeita o agente de produção às seguintes percepções de riscos:

- Elevado custo de aquisição ou de arrendamento do solo.

- Conflitos, paralisações e multas, em decorrência da expansão urbana desordenada.

- Complexidade de processos de licenciamento ambiental.

- Instabilidade da outorga mineral, quando fundamentada em Regime de Licenciamento.

Cumpre ressaltar que o Regime de Licenciamento não requer a atividade prévia de pesquisa mineral, enquanto o regime alternativo (de Autorização e Concessão) confere maior estabilidade ao investidor, além de lhe assegurar conhecimentos (oriundos de pesquisa mineral) imprescindíveis à promoção da competitividade e da sustentabilidade de seus empreendimentos.

Em função das percepções de risco, as empresas optam, usualmente, por soluções que minimizem investimentos, mediante o comprometimento de áreas mais reduzidas do que as que seriam requeridas para uma extração de areia ou de rocha dura em bases mais racionais. Condicionam-se, portanto, a sítios comprimidos e, conseqüentemente, à adoção de técnicas rudimentares associa-

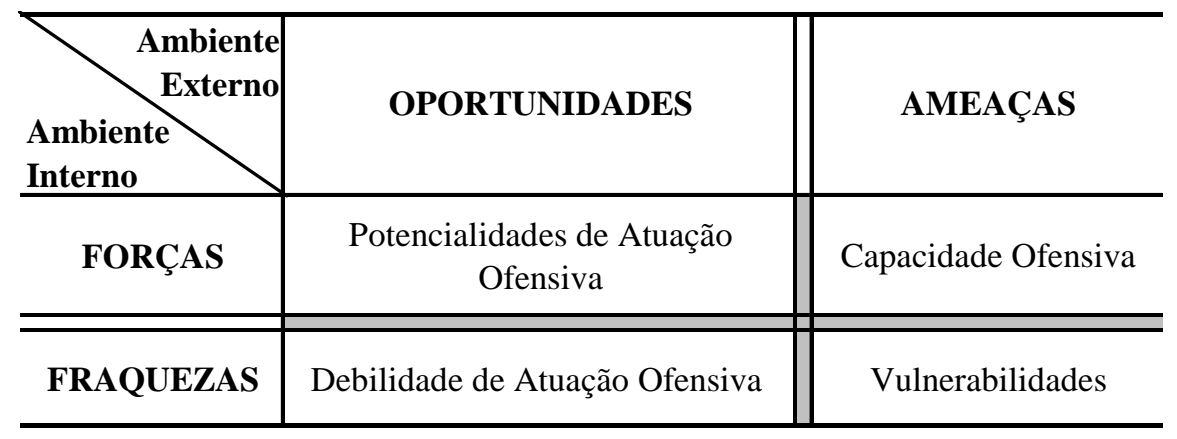

Figura 2 - Análise estratégica - matriz swot. 
Bases para o desenvolvimento sustentável e competitivo da indústria de agregados nas ...

das a piores condições de trabalho, do que decorrem custos acentuados de produção com sérios prejuízos, seja sob o ponto de vista competitivo da empresa ou dos impactos ambientais associados.

\subsubsection{Tecnologia de processo}

Sob o ponto de vista da tecnologia de processo, sobressaem, na extração de rocha dura, as vantagens da lavra em bancadas, cujos benefícios repercutem sobre o processo de beneficiamento.

\section{- Método de Lavra}

- Lavra em paredão: Utiliza perfuratrizes manuais e explosivos de menor eficiência, resultando em menor homogeneidade do material extraído, com queda de eficiência da britagem primária, devido à maior irregularidade do material na alimentação. Resulta também numa maior freqüência de fogo secundário, com maiores riscos de lançamento de fragmentos.

- Lavra em bancadas: Embora com maior exigência de área para construção de vias de acesso aos diferentes níveis dos trabalhos de desmonte, assegura o emprego de perfuratrizes de carreta e a adoção de planos de desmonte de maior eficiência, daí decorrendo a geração de material mais uniforme, com menor necessidade de fogo secundário e melhor regime de alimentação da britagem. Assegura-se, assim, a melhoria de produtividade e a redução de custos unitários de produção, com a conseqüente redução de impactos ambientais, em função do melhor aproveitamento dos recursos naturais.

- Processos de beneficiamento: No beneficiamento, a alimentação da britagem primária com material mais homogêneo, proveniente de lavra com técnicas adequadas de desmonte, propicia uma maior eficiência do processo, além de uma possível redução na geração de finos e de material particulado. Ainda com relação aos circuitos de beneficiamento, cabe destacar os seguintes aspectos condicionadores do ordenamento territorial e da sustentabilidade:
- O processamento de rochas com tendência lamelar pode exigir estágios adicionais de britagem, com maiores custos e impactos ambientais. Conseqüentemente, a adequada seleção e o conhecimento técnico-científico do depósito representam fatores relevantes na promoção das condições de produtividade e de competitividade privada e social do empreendimento.

- Se, por um lado, o despoeiramento por umidificação permite solucionar o problema do lançamento de material particulado, por outro, como decorrência, o material pulverulento agregado à brita tem excedido o limite de $1 \%$ definido pela ABNT (NBR 7211).

- Exigências ambientais crescentes, referentes à emissão de particulados, bem como rigorosas especificações de qualidade deverão exigir mudanças nas unidades de beneficiamento, evidenciando uma tendência à adoção dos circuitos de processamento encapsulados.

A comparação de resultados de dois levantamentos realizados no pólo de brita da RMRJ - o primeiro realizado em 1980 (DRM/RJ, 1981) e o segundo em 2002 (Calaes et al., 2002) - evidencia a interação de fatores regulatórios e tecnológicos com o ordenamento territorial.

Constata-se que, em 1980, apenas 17\% das unidades de produção de brita (UPs) operavam sob o regime de concessão. Portanto 83\% sujeitavam-se ao regime de licenciamento, sujeito a renovações periódicas pelas prefeituras municipais, não oferecendo, portanto, a necessária estabilidade e segurança para a realização de investimentos. Conseqüentemente, as UPs que operam sob o regime de licenciamento possuem um perfil tecnológico usualmente inferior àquelas sujeitas ao regime de concessão. Cumpre ressaltar que - além de conferir maior estabilidade e segurança a investimentos - o regime de concessão exige a realização de trabalhos de pesquisa mineral como condição para a obtenção da outorga de lavra.
Ainda sob o ponto de vista regulatório, verifica-se que, em 2002, 61\% das UPs operavam sob o regime de concessão e, portanto, 39\% permaneciam no regime de licenciamento. Constata-se, portanto, uma nítida migração das UPs do regime de maior instabilidade (licenciamento) para o regime de maior estabilidade (concessão). Cabe, também, assinalar que, em 2002, 87\% das UPs operavam pelo método de bancada, em contrapartida a 31\% observado em 1980.

Evidencia-se, portanto, uma nítida interação entre o sistema de outorga (fator regulatório) e o método de lavra (fator tecnológico), permitindo concluir que mudanças de cunho legal estimulam aprimoramentos tecnológicos, com relevantes efeitos em termos de ordenamento territorial e melhoria ambiental, conforme já evidenciado na análise comparada de impactos dos métodos de paredão e de bancada.

A Figura 3 assinala as mudanças tecnológicas constatadas nas operações de lavra e de beneficiamento, no parque produtor de brita da RMRJ, sob efeito de mudanças no regime de outorga das UPs, no período 1980-2002.

\subsubsection{Tecnologia de produto}

Sob o ponto de vista da tecnologia de produto, a produção de areia de brita e o reprocessamento de ECD evidenciam oportunidades de elevada contribuição para o ordenamento do território e melhoria das condições de sustentabilidade.

Areia de Brita (AB): Quer seja obtida dos finos de britagem ou a partir da rocha dura, a AB oferece interessantes perspectivas. No primeiro caso, devido ao formato lamelar ou alongado das partículas contidas nas frações mais finas do pó de pedra, o mercado mais afeiçoado ao subproduto $A B$ é o de base e sub-base de pavimentação. No segundo caso, a utilização de novos processos e equipamentos têm propiciado a obtenção de AB com partículas arredondadas. As características do co-produto $\boldsymbol{A B}$ correspondem 
às especificações de diferentes segmentos do mercado da construção civil. AABNT (NBR 9935) recomenda a expressão areia de britagem para designar o agregado miúdo oriundo de processo de cominuição mecânica da rocha. Entretanto, aos autores desse artigo, a expressão areia de brita afigura-se mais adequada,.

Agregado oriundo de ECD: Apesar de ainda pouco praticada no Brasil, a reciclagem de entulho de construção e demolição (ECD) já é realizada há mais de 30 anos na América do Norte e na Europa, sendo, predominantemente, utilizada para compor base e sub-base de pavimentação. Embora as expressões ECD (Entulho de Construção e Demolição) e RCD (Resíduo de Construção e Demolição) venham sendo igualmente difundidas, os autores assinalam preferência pela primeira.

\subsection{A reversão de conflitos locacionais e ambientais}

Os processos de ordenamento territorial devem levar em consideração a importância e a contribuição das diferentes atividades econômicas, para o desenvolvimento regional, bem como os respectivos impactos e superfícies envolvidas.

\subsubsection{Contextos e experiências européias}

Regueiro (2006) assinala que a superfície da Europa afetada por contaminação de pesticidas e nitratos, associada a atividades agrícolas, é de 600 a 1.200 vezes maior do que a afetada pelas atividades da mineração. Destaca, também, que a agricultura moderna gera uma renda anual média da ordem de US\$ 900 / ha; a pecuária, US\$ 300 / ha; e a mineração, entre US\$ 60.000 / ha (média de 100 atividades de extração do nordeste brasileiro) e US\$260.000 / ha (média verificada na produção mundial da Rio Tinto, em 1997).

Assinala, ainda, que, na Alemanha, 0,5\% do território está coberto por direi-

\section{Tecnologia, Legislação e Ordenamento do Território}

\section{Mudanças Tecnológicas em 20 anos na RMRJ \\ - Na Lavra (Participação \%)}

\begin{tabular}{lcc}
\multicolumn{1}{c}{ Mudanças } & $\mathbf{1 9 8 0}$ & $\mathbf{2 0 0 2}$ \\
- Concessões de Lavra & 17 & 61 \\
- Bancada & 31 & 87 \\
- Perfuratriz de Carreta & 33 & 87 \\
- Linha Silenciosa & - & 76 \\
- Rompedor Hidráulico & - & 59
\end{tabular}

\section{- No Beneficiamento}

- Capacidade de Britagem Primária

- Estágios de Rebritagem

- Estoques em Pilha com Retomada Inferior

- Maior Eficiência em Classificação

- Automação Operacional e Gerencial tos minerais e somente 0,01\% está afetado por atividade de mineração. Na Inglaterra, as outorgas de lavra a céu aberto cobriam, em 1999, 0,7\% do território e metade dessa superfície já havia sido restaurada.

Ao analisar o ordenamento territorial na Espanha, Barattino (2006) registra que, nos 179 municípios compreendidos pela Comunidad de Madrid, 55,2\% do solo é classificado como especial protegido, 8,6\% como solo urbano e 4,2\% como solo urbanizável. Em Portugal, segundo Carvalho e Martins (2006), a questão do ordenamento territorial (OT) é tratada por diferentes instrumentos institucionais, seja em âmbito federal (Política Nacional, Planos Setoriais e Planos Especiais de OT), regional (Planos Regionais de OT), ou municipal (Plano Diretor Municipal).

Sob o ponto de vista da acessibilidade do recurso geológico, a produção de agregados, naquele país, lida, atualmente, com inúmeras restrições de uso e ocupação do solo, salientando as áreas de proteção natural, as áreas urbanas, industriais e agrícolas, as áreas com restrição militar, os rios e represamentos de água, além de traçados de estradas, ferrovias, rede de transmissão de energia, oleodutos, gasodutos, etc.

\subsubsection{Brasil: tendências dominantes e medidas de ordenamento}

Segundo Calaes (2005, apud Pimiento, 2000), a indústria mineral não ocupa mais do que $0,13 \%$ da superfície terrestre da Colômbia ou do que $0,25 \%$, dos EUA. No Brasil, segundo Albuquerque e Calaes (2002), as 32 pedreiras produtoras de brita na RMRJ ocupam uma superfície total de 3.000 ha, ou seja, $0,5 \%$ da superfície da região.

Diante das questões regulatórias e tecnológicas anteriormente assinaladas e admitindo-se a manutenção do atual quadro de evolução natural do mercado de agregados nas RMs, pode-se prever as seguintes tendências dominantes, 
associadas às atuais empresas produtoras:

- Empresas em conflito com a expansão urbana e com baixa propensão à relocação serão expurgadas do mercado.

- Empresas em conflito com a expansão urbana e com boa instrumentação tecnológica, gerencial e econômica tenderão a manter as suas atuais localizações ou a optar pela relocação para locais onde possam fortalecer suas posições competitivas.

- Empresas com localizações isentas de conflitos com a expansão urbana e com boa instrumentação tecnológica, gerencial e econômica tenderão a fortalecer suas competitividades.

Na reversão dos atuais conflitos locacionais e ambientais que envolvem a produção de agregados nas RMs, as ações mitigadoras pontuais devem ser complementadas por medidas de zoneamento de uso e ocupação do solo, seja para garantir a segurança e estabilidade institucional aos produtores, em suas atuais localizações, ou para estimular relocações, nos casos de difícil reversão. Além de ordenamento territorial (OT), a reversão dos atuais conflitos exigirá, também, importantes saltos tecnológicos, seja no que se refere aos processos de lavra e beneficiamento, ou em nível da tecnologia de produto, onde se destacam as oportunidades de produção de areia de brita e de reprocessamento de ECD.

\section{O planejamento da produção de agregados em RMs}

Ao se empreenderem atividades de planejamento da produção de agregados, deve-se ter em conta que a demanda de tais materiais é condicionada pelo fluxo de investimentos em obras de infra-estrutura regional (transporte, energia e saneamento), bem como de infra-estrutura urbana e metropolitana (pavimentação de vias, adução de água, saneamento, etc.). A demanda é, também, condicionada pelo fluxo e composição de edi- ficações residenciais, industriais e de serviços.

Diante da continuada expansão da população mundial, acompanhada da intensificação da taxa de urbanização, o suprimento de agregados para atendimento às necessidades de expansão dos centros urbanos passou a ser uma questão em destaque na agenda do planejamento urbano e do desenvolvimento sustentável.

\subsection{0 contexto norte- americano}

Nos EUA, a produção de agregados corresponde à metade do volume de toda a produção mineral, excetuando os combustíveis. Cerca de 4.000 empresas produzem areia e cascalho, a partir de mais de 6.000 unidades de produção. A produção de brita é da ordem de 1 bilhão $\mathrm{m}^{3}$ /ano, realizada por cerca de 1.500 empresas e 3.500 pedreiras, distribuídas por 48 estados do país. De acordo com o American Geological Institute (AGI), mais de 100 minas subterrâneas de rocha dura (principalmente calcário e dolomita) produzem brita naquela país.(Langer et al, 2004).

Cinco empresas concentram cerca de $25 \%$ do volume total de produção de agregados. Cinco das dez maiores empresas produtoras de brita e 3 das 10 maiores produtoras de areia e cascalho são estrangeiras. O acesso a reservas minerais de qualidade superior tem sido uma das principais motivações para fusões e aquisições, cada vez mais freqüentes, na indústria americana de agregados.

Cerca de 93\% da produção de agregados é transportada por caminhões, 3\% por ferrovia e $4 \%$ por chatas e navios. Entre os cuidados ambientais mais difundidos, destaca-se a recuperação da área minerada, salientando-se o aproveitamento das cavas para construção de condomínios e shopping centers, para disposição e reciclagem de ECD, ou ainda para aterros de resíduos. A reciclagem de ECD alcança volumes superiores a 100 milhões t/ano.

\subsection{0 contexto europeu}

Segundo Regueiro (2006), a Europa (25 países) contava, em 2002, com cerca de 11 mil produtores de agregados, perfazendo uma produção anual da ordem de 2,8 bilhões t: areia e cascalho: $45 \%$; rocha britada: $47 \%$ e agregado reciclado: 7\%. Pela ordem, os principais produtores, naquele ano, foram Alemanha, Espanha, França, Itália e Inglaterra, os quais respondem por cerca de 2/3 de toda a produção européia. Nesses países, os consumos per capita (em t/habitante/ano) são de 4,2, 9,4, 6,4, 6,3 e 3,7, respectivamente. A propósito, o consumo per capita médio da Europa, em 2002, foi de 7,1 t. Naquele ano, os maiores consumos per capita foram observados na Irlanda, Luxemburgo e Finlândia (27,8, 17,9 e 17,2, respectivamente) e os menores na Lituânia, Eslováquia e Polônia $(1,7,2,0$ e 2,3).

Destaca-se a racionalização do transporte de agregados, com a utilização de barcaças com capacidade de 2 mil t, operando, produtivamente, em lances iguais a $200 \mathrm{~km}$ ou maiores do que esta quilometragem, enquanto o transporte rodoviário torna proibitivas as distâncias superiores a $30 \mathrm{~km}$. A Europa exerce, também, a liderança mundial na reciclagem de ECD, sobressaindo a Holanda, onde $70 \%$ de tais resíduos são reciclados.

Hebestreit (2006), assinala que os principais desafios da mineração de agregados, na Europa, estão associados às exigências de implementação de uma nova legislação, à reestruturação do setor produtivo e à necessidade de estimular a competitividade. Reconhece que a superação de tais desafios requer um amplo sistema público de cooperação e participação, de que participem não apenas os produtores e as autoridades locais e regionais, como também as instituições de P\&D, sindicatos e ONGs. Exige, também, a disseminação de idéias inovativas, o fortalecimento da imagem da indústria extrativa e de sua atitude positiva na realização de investimentos de interesse para as economias regionais.

Os tópicos seguintes buscam caracterizar o panorama de agregados em alguns países da Europa: 
Alemanha: É o maior produtor europeu, com 550 milhões t, em 2003. Destacase a intensificação de demanda a partir da reincorporação da Alemanha Oriental. Em 2003, a reciclagem de ECD participou com $16 \%$ do total da produção de agregados.

Espanha: Com território de $8 \mathrm{mil} \mathrm{km²} \mathrm{e}$ população da ordem de 6 milhões de habitantes, a Comunidad de Madrid (CM) responde por $13 \%$ da população espanhola e por $17 \%$ do PIB, sendo a região com maior renda per capita do país. Segundo Barettino (2006), em 2004, o consumo per capita de agregados, da $C M$, era de 7,6 t e o da Espanha de $10,7 \mathrm{t}$. Em 2005, a CM contava com 96 unidades de produção de brita e/ou areia, submetidas a desafios de ordenamento territorial, tendo em vista que $40 \%$ do território da $C M$ é constituído por lugares de interesse comunitário e $14 \%$ por espaços naturais protegidos (parques, monumentos naturais, sítios de interesse, refúgio de fauna, etc.).

França: Na França, onde o consumo per capita de agregados é de 6,4 t/hab/ano, a produção (cerca de 400 milhões t, em 2003) enfrenta vigorosas restrições ambientais: dos cerca de 9 bilhões t de reservas minerais passíveis de atender o mercado de agregados da RM de Paris, 7,5 bilhões estão situadas em áreas protegidas. Em conseqüência, observa-se a expansão dos preços de agregados, cabendo lembrar que um aumento de $30 \mathrm{~km}$ na distância de transporte representa acréscimo de 60\% no consumo de óleo diesel.

Portugal: Em Portugal, são obrigadas a elaborar um Estudo de Impacto Ambiental (EIA) todas as pedreiras com produção superior a 150.000 t/ano e as que detenham área superior a 5 ha ou as que, encontrando-se num raio de 1 $\mathrm{km}$ de outras pedreiras, possam, no seu conjunto, ultrapassar os limites referidos, ou, ainda, aquelas que, embora dentro dos limites previstos, venham a receber tal exigência. Entre os principais marcos que regulam a produção de agregados, destacam-se a obrigatoriedade de prestação de uma caução à entidade responsável pelo Plano Ambiental e de Recuperação Paisagística (PARP), a possibilidade de fusão de pedreiras confinantes no mesmo Plano de Pedreira, e a definição de critérios para ordenamento do território e para o processamento de ECD.

Reino Unido: Cerca de 75\% da produção de agregados apresenta-se concentrada em cinco grupos. A baixa dinâmica do mercado de agregados (consumo per capita de 3,7 t/habitante/ano em 2002) não deverá perdurar, tendo em vista o envelhecimento de infra-estruturas. Em 2003, a Inglaterra produziu cerca de 270 milhões $t$ de agregados, dos quais $23 \%$ a partir da reciclagem deECD.

\subsection{O Contexto latino- americano}

O panorama, a seguir apresentado, de três países sul-americanos oferece uma visão de ameaças e obstáculos comuns a outras regiões do continente.

Colômbia: Em Bogotá (com 10 milhões de habitantes e situada a $3.400 \mathrm{~m}$ de altitude), grande parte da produção que abastece o mercado é originária de cascalho de origem glacial. As "graveras”, localizadas na savana de Bogotá, exigem uma delicada gestão territorial e ambiental, pois a produção de agregados (miúdo e graúdo) requer a retirada do capeamento do solo, até que se atinja a camada com agregado, o qual é extraído e destinado a circuito de lavagem, separação, britagem e classificação. O avanço da extração é combinado com a recomposição do solo de forma a favorecer os demais usos da superfície, notadamente pecuária, agricultura e cultivo de flores. Especial cuidado é adotado com a gestão da água, a qual é escassa na região e é intensamente exigida no processo. A sua reutilização em circuito fechado, combinadamente com um sistema de reaproveitamento de água de chuva, reduz a necessidade de "make up" para patamares da ordem de $15 \%$.
Costa Rica: Na Costa Rica, a mineração aluvionar responde por cerca de $40 \%$ do suprimento de agregados para construção, dispondo de significativos recursos geológicos, ampla distribuição e facilidades de extração e processamento. No futuro próximo, tal participação deverá aumentar, tendo em vista a ausência de um adequado ordenamento territorial e os múltiplos problemas ambientais associados à operação de pedreiras próximas à RM de San José, envolvendo conflitos de uso e ocupação do solo, poeira, ruído, vibrações, circulação de veículos, restrições ambientais, etc.

República Dominicana: Na República Dominicana, a extração de agregados é a causa do principal conflito de ordenamento territorial mineiro, já que provoca alterações nos leitos, nas margens e nas águas dos principais rios do país. Leon (2006) aponta as seguintes razões para os conflitos que impedem o ordenamento territorial mineiro no país: i) Atividades extrativas inadequadamente conduzidas nos principais rios; ii) Superposições de outorgas de mineração com áreas protegidas; iii) Falta de articulação entre autoridades do meio ambiente e da mineração; e iv) Falta de vontade política para implementar o ordenamento territorial.

\section{O panorama nacional}

No Brasil, segundo o DNPM (2006), a produção de agregados para construção civil, em 2005, foi da ordem de 331 milhões t, com crescimento de 4,8\% em relação a 2004. Deste total, as pedras britadas participam com 135 milhões t (41\%) e a areia, com 196 milhões t. O Estado de São Paulo participou com $42 \%$ da produção nacional de agregados, em 2005, sendo seguido por Minas Gerais (12,5\%), Rio de Janeiro (11\%), Paraná (6,5\%); Rio Grande do Sul (6,3\%) e Santa Catarina $(3,5 \%)$.

A produção nacional de brita envolve 660 empresas, com 20 mil empre- 
gos diretos e 100 mil indiretos. Da análise da distribuição de tais empresas, segundo o volume de produção, verificase que $10 \%$ apresenta produção superior a 500 mil t/ano, $30 \%$ entre 200 mil e 500 mil t/ano e 60\% inferior a 200 mil t/ano. Verifica-se, também, a seguinte distribuição aproximada da produção de brita, segundo a rocha utilizada: Granito e gnaisse: 85\%, calcário e dolomita: $10 \%$ e basalto e diabásio: 5\%.

A produção nacional de areia é realizada por cerca de 2.500 unidades de extração com 50 mil empregos diretos e 150 mil indiretos. Cerca de $60 \%$ de tais unidades produz menos que $10.000 \mathrm{t} /$ mês, 35\% entre 10.000 e 25.000 t/mês e $5 \%$ acima de 25.000 t/mês. Verifica-se que $70 \%$ da areia produzida se origina de leitos dos rios e 30\% de várzeas.

Pelo lado da demanda, verifica-se que $70 \%$ do consumo de brita encontrase associado à mistura com cimento e $30 \%$ com asfalto betuminoso. No segmento associado à mistura com cimento, verifica-se a seguinte distribuição: concreto (35\%), pré-fabricados (15\%), revenda $(10 \%)$ e os $10 \%$ restantes são destinados a enrocamento, gabiões, cascalhamento, lastro de ferrovia, construção de taludes, etc. Por sua vez, os 30\% destinados à mistura com asfalto betuminoso compreende a construção de ruas e rodovias, incluindo base e sub-base de pavimentação.

Os tópicos subseqüentes oferecem elementos básicos de caracterização dos principais pólos brasileiros de produção e consumo de agregados:

Bahia: Na RM de Salvador, verificam-se os problemas típicos de outras RMs, no que se refere ao conflito entre a produção de agregados e a expansão urbana.

Distrito Federal: Na RM do Distrito Federal, a oferta de brita é realizada por nove empresas, a maior das quais com capacidade de 70 mil t/mês. Salientase a tendência à substituição da areia natural, por areia de brita.

Espírito Santo: Na RM de Vitória, as pedreiras conseguiram criar uma faixa de proteção de forma a prevenir conflitos. O déficit de areia natural da RM é significativo.

Paraná: Verificam-se uma alta participação de brita de basalto, e a existência de regiões que dependem de suprimentos oriundos de distâncias superiores a $100 \mathrm{~km}$.

Rio de Janeiro: Na RMRJ, 40\% da produção de brita se destina ao consumo intermediário, em 32 unidades de concreto asfáltico, 31 de concreto usinado e cerca de 1.000 de artefatos de concreto. A cadeia industrial da brita na RMRJ congrega 40 mil postos de trabalho (cerca de 1.200 na produção da brita).

Rio Grande do Sul: O Estado conta com cerca de 100 pedreiras em atividade, das quais 15 localizadas na RM de Porto Alegre. A maioria das pedreiras das RM de Porto Alegre produzem brita a partir do basalto.

Santa Catarina: A produção de areia apresenta relativa concentração nas bacias dos rios Itajaí e Itapocu, que respondem por cerca de $40 \%$ do total estadual.

São Paulo: Face ao esgotamento de depósitos e a conflitos de uso e ocupação do solo, o suprimento do mercado da RM tem exigido deslocamentos de produto em distâncias superiores a 100 $\mathrm{km}$. A areia de brita já apresenta participação entre 5 a 10\% do mercado de areia para construção da RM.

Além de vários exemplos que evidenciam mudanças no perfil estratégico de empresas e empreendimentos produtores de agregados, destaca-se, em Minas Gerais, o caso de uma uinidade produtora de brita e areia, localizada em Juiz de Fora. Com capacidade de 1,5 milhões t/ano, tal unidade incorpora concepções avançadas de engenharia de minas, de planejamento e gestão da produção e comercialização e de articulação com a comunidade. Com a implantação da pedreira, o capeamento passou a ser utilizado para transformar um antigo lixão em aterro sanitário, viabilizando a instalação de um moderno pólo industrial, co- mercial e de serviços. Por outro lado, concomitantemente com a obtenção de licença de instalação pelo prazo de 50 anos, foi aprovada a criação de uma área de proteção de dois quilômetros, em torno da pedreira. $\mathrm{O}$ empreendimento se destaca, também, pela produção de areia de brita via seca, como co-produto. Destaca-se, ainda, pela integração com unidades produtoras de concreto usinado, que se instalaram em área contígua, transferindo-se das cercanias de uma pedreira antiga, que foi adquirida e desativada pelo mesmo grupo empreendedor. Aárea da antiga pedreira foi reaproveitada com a instalação de um centro comercial automotivo e de um espaço para grandes eventos ao ar livre, ambientado na antiga praça de operações, junto ao paredão da unidade de extração desativada.

Na complementação desse artigo, a ser publicada na próxima edição deste periódico, serão abordados o Caso do Parque Produtor de Brita da RMRJ e a indicação de políticas públicas necessárias para estímulo ao desenvolvimento competitivo e sustentável do setor, nas RMs do país.

\section{Referências bibliográficas}

ALBUQUERQUE, G., CALAES, G. Estudo do Parque Produtor de Brita da RMRJ: índices preliminares de sustentabilidade. In: VILLAS BÔAS, R., BEINHOFF, C. (eds.). Indicadores de Sostenibilidad para la Industria Extractiva Mineral. Rio de Janeiro: GEF, CBPq/CYTED, 2002. 564 p.

ALLER, R. F. El crecimiento de Madrid y la industria de los Áridos (agregados). In: SEMINÁRIO INTERNACIONAL MINERIA, MÉDIO AMBIENTE Y ORDENAMENTO TERRITORIAL, 2. Bogotá, Colômbia, 2006.

BARETTINO, D. La visión de la autoridad ambiental frente a las actividades extractivas de materiales de construcción. In: SEMINÁRIO INTERNACIONAL MINERIA, MÉDIO AMBIENTE Y ORDENAMENTO TERRITORIAL, 2. Bogotá, Colômbia, 2006. 
Gilberto Dias Calaes et al.

BRAND, P. La Construcción ambiental del bienestar urbano. Caso de Medellín, Colombia. In: Economía, Sociedad y Territorio. [S.l.], 2001. v. 3, p. 1-24.

CALAES, G. Competitividade $\boldsymbol{e}$ sustentabilidade na indústria mineral. Palestra apresentada na VII Conferência Internacional sobre Tecnologias Limpas para a Indústria Mineral, Búzios, out/ 2006.

CALAES, G., NETTO, B., AMARAL, J. Estudo do parque produtor de brita da região metropolitana do Rio de Janeiro. 2002. $245 \mathrm{f}$. Trabalho realizado para o DG / IGEO / CCMN / UFRJ com apoio do CT-Mineral, Rio de Janeiro, 2002.

CALAES, G. O planejamento estratégico do desenvolvimento mineral sustentável e competitivo - dois - caso de não metálicos no Rio de Janeiro. Rio de Janeiro: Departamento de Geologia do Instituto de Geociências da UFRJ, 2005. $298 f$. (Tese de Doutorado).

CALAES, G., AMARAL, J.A.G., PIQUET, B. Desenvolvimento sustentável do mercado de brita no Rio de Janeiro Brasil: planejamento estratégico participativo na solução de conflitos locacionais. 2003. Trabalho apresentado no III Seminário Recursos Geológicos,

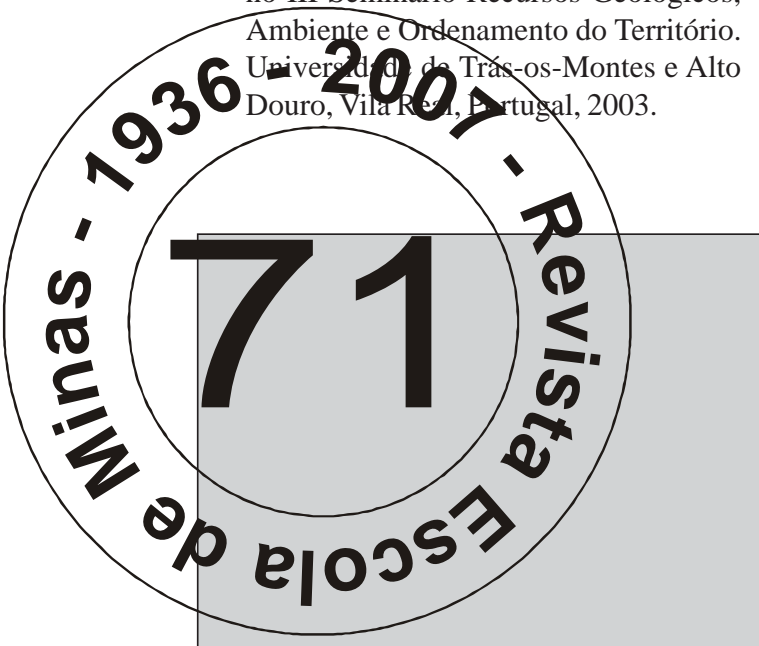

CARVALHO, J. E MARTINS, L. Panorámica de la extracción de agregados en Portugal Ambiente y Ordenamiento Del Territorio. In: SEMINÁRIO INTERNACIONAL MINERIA, MÉDIO AMBIENTE Y ORDENAMENTO TERRITORIAL, 2. Bogotá, Colômbia, 2006.

DRM/RJ - Departamento de Recursos Minerais do Estado do Rio de Janeiro. Estudo do Parque Produtor de Brita da região metropolitana do Rio de Janeiro. Estudo contratado com GEOMITEC/CONDEP, 1980/81.

HEBESTREIT, C. The license to operate: a european perspective. In: SEMINÁRIO INTERNACIONAL MINERIA, MÉDIO AMBIENTE Y ORDENAMENTO TERRITORIAL, 2. Bogotá, Colômbia, 2006.

LANGER, W., DREW, L., SACHS, J. Aggregates and the Environment. American Geological Institute in cooperation with U.S. Geological Survey, AGI Environmental Awareness Series, 2004. 64 p.

LEON, R. O. Los conflictos para el ordenamiento territorial en las áreas mineras de República Dominicana: un caso particular. In: SEMINÁRIO INTERNACIONAL MINERIA, MÉDIO AMBIENTE Y ORDENAMENTO TERRITORIAL, 2. Bogotá, Colômbia, 2006.

PORTER, M. E. Estratégia competitiva: técnicas para análise de indústrias e da concorrência. 9. Ed. Rio de Janeiro: Campus, 1986.

REGUEIRO, M. La extracción de áridos en la unión europea en el marco de la estrategia del uso sostenible de los recursos naturales. In: SEMINÁRIO INTERNACIONAL MINERIA, MÉDIO AMBIENTE Y ORDENAMENTO TERRITORIAL, 2. Bogotá, Colômbia, 2006.

VIEIRA, A. Situação no sector da produção de agregados em Portugal - perspectivas futuras e projectos para a resolução dos problemas actuais. In: SEMINÁRIO INTERNACIONAL MINERIA, MÉDIO AMBIENTE Y ORDENAMENTO TERRITORIAL, 2. Bogotá, Colômbia, 2006.

VILLALÓN, F. A. Minería aluvial de agregados, recuperación ambiental y ordenamiento territorial en Costa Rica. In: SEMINÁRIO INTERNACIONAL MINERIA, MÉDIO AMBIENTE Y ORDENAMENTO TERRITORIAL, 2. Bogotá, Colômbia, 2006.

WACKERNAGEL, M. La Huella Ecológica de las Ciudades. Como Asegurar el Bienestar Humano dentro de los Limites Ecológicos?. Paper utilizado na disciplina Sustentabilidade e Cidade, cursada no IPPUR/UFRJ; Programa de Pós-Graduação em Geologia Regional e Econômica; DG/IGEO/CCMN/UFRJ. 1996. 9 p.

\section{Artigo recebido em 02/03/2007 e aprovado em 20/08/2007.}

\title{
REM - Revista Escola de Minas 71 anos divulgando CIÊNCIA.
}

\author{
$\star \star * * * *$ \\ www.rem.com.br \\ ******
}

